Anuario da Facultade de Dereito da Universidade da Coruña

Vol. 20 (2016), pp. 139-160

ISSNe: 2530-6324 || ISSN: 1138-039X

DOI: https://doi.org/10.17979/afdudc.2016.20.0.1918

\title{
LOS PROGRAMAS Y ACTIVIDADES DEL TRATAMIENTO PENITENCIARIO: LA NECESARIA ADAPTACIÓN DE LA NORMA
}

\author{
DRA. Rosa M. Gallardo GARCÍA \\ Profa. Sustituta interina de Derecho Procesal \\ Universidad de Cádiz
}

Fecha de recepción: 30.6.2016

Fecha de aceptación: 18.7.2016

\begin{abstract}
Resumen: La normativa penitenciaria apenas ha sufrido cambios desde que se aprobó, por lo que la falta de interés por reformar y adaptar esta materia llama la atención. El tratamiento penitenciario, eje del sistema penitenciario, ha evolucionado en los últimos años dentro de los muros de las prisiones, transformando alguno de sus elementos por lo que parece necesario revisar el contenido de las principales leyes penitenciarias.
\end{abstract}

Palabras clave: prisión; tratamiento penitenciario; reforma normativa

Abstract: The prison legislation has not hardly changed since it was approved, so the lack of interest in reforming and adapting this matter is striking (attracts attention). The prison treatment, axis of the prison system, has evolved in recent years within prison walls, transforming some of its elements; therefore it seems necessary to review the content of the main prison laws.

Key words: prison; penitentiary treatment; penitentiary reform 
SUMARIO: I.- INTRODUCCIÓN. II.- APROXIMACIÓN A UNA DEFINICIÓN DE TRATAMIENTO PENITENCIARIO. III.- ESTUDIO DE LOS PROGRAMAS Y LAS ACTIVIDADES TRATAMENTALES DESARROLLADAS EN LOS CENTROS PENITENCIARIOS. IV.- LA NECESARIA REFORMA LEGISLATIVA EN EL ÁMBITO DE LOS PROGRAMAS DE TRATAMIENTO

\section{I.- INTRODUCCIÓN}

El Derecho penitenciario tiene su propio sistema de fuentes, de ahí que se considere una rama autónoma del Derecho. Este acervo lo componen normas de muy distinta naturaleza, siendo el eje del mismo la LOGP $^{1}$, siguiéndole en orden de importancia el $\mathrm{RP}^{2}$. Aunque éstas son las más conocidas y reconocidas no son las únicas de rango legal o reglamentario, también en el Código penal se regulan cuestiones importantes de la ejecución de la pena. Tampoco podemos obviar el importante desarrollo que esta materia ha tenido vía potestad reglamentaria de la Administración penitenciaria, a través de instrucciones y circulares, que ha ido atendiendo a las distintas necesidades que la práctica penitenciaria dentro de los muros de las prisiones iba generando.

La LOGP fue la primera ley de la entonces naciente y joven democracia española, y consiguió nada más nacer hacerse con el adjetivo de "moderna". Efectivamente su aprobación trajo consigo grandes avances en un ámbito que precisaba con urgencia un cambio importante de paradigma. El más significativo fue la separación entre el régimen y el tratamiento, definiendo con claridad los aspectos diferenciadores de los mismos.

Desde que se comenzó a conformar este corpus penitenciario éste ha sufrido escasas reformas. Sin embargo, la realidad de las prisiones ha evolucionado con el tiempo. Estos cambios precisan ser evaluados atendiendo a la realidad penitenciaria para posteriormente analizar la necesidad de regulación de los mismos. Esta investigación tiene como objetivo determinar qué cuestiones tratamentales precisan de una reforma legislativa. Así pues, en las páginas siguientes nos vamos a centrar en el estudio de la regulación del tratamiento penitenciario dado el importante papel que ocupa en el ámbito del fin que orienta las penas privativas de libertad, como la reinserción social.

Para ello, vamos a partir de una definición de tratamiento que nos aportará el marco teórico adecuado para la posterior evaluación de las distintas actividades y programas tratamentales que existen. Dada la variedad de actividades y programas dentro de las diferentes prisiones que pueblan el territorio de nuestro país, una evaluación completa sería una tarea difícil de abarcar en esta investigación, por lo que se pretende nombrar la mayor parte de ellos, sin ánimo de exhaustividad, y nos detendremos en aquellos mencionados por la normativa expresamente.

\footnotetext{
${ }^{1}$ En adelante se utilizará esta forma abreviada para referirnos a la Ley Orgánica 1/1979, de 26 de septiembre, General Penitenciaria.

${ }_{2}^{2}$ En adelante se utilizará esta forma abreviada para referirnos al Real Decreto 190/1996, de 9 de febrero, por el que se aprueba el Reglamento Penitenciario.
} 
Además se hará referencia a algunos que sin aparecer en la norma han cobrado gran importancia por su implementación en prácticamente todos los centros penitenciarios, y se prescindirá de otras herramientas tratamentales que, dada su importancia, precisarían de un estudio con mayor protagonismo, como es la educación y el trabajo penitenciario. Ambos mecanismos son ejes del tratamiento penitenciario moderno y son los que consiguen dotar al mismo de la naturaleza sociológica que éste precisa, además de ser los que gozan de mayor desarrollo teórico, por lo que resulta complicado abarcar en esta investigación toda su dimensión.

A partir del estudio de la realidad tratamental que se da en los centros penitenciarios, evaluaremos la necesidad de adaptar la normativa penitenciaria a la práctica que se desarrolla dentro de los muros de las prisiones. Esta evaluación pretende considerar las ventajas de una posible reforma normativa mediante una reflexión sobre la evolución del contenido de los programas y actividad tratamentales.

\section{II.- APROXIMACIÓN A UNA DEFINICIÓN DE TRATAMIENTO PENITENCIARIO}

La aprobación de la Constitución española trajo consigo una redefinición de la finalidad de la pena privativa de libertad en nuestro país. La entrada de la democracia en un intento de humanización de las sanciones y de las condiciones de cumplimiento de las mismas, supuso un giro sustantivo en la pena privativa de libertad en particular, otorgando un contenido social a la misma, superando la concepción retributiva tradicional al exigir su orientación a la reinserción y a la reeducación del sujeto condenado tras la comisión de un delito ${ }^{3}$.

A partir de 1978 la pena privativa de libertad en nuestro país tiene como objetivo principal la resocialización de aquellas personas que cumplen condena ${ }^{4}$, cobrando especial significado cuando se trata de la privación de libertad, y dado que el sujeto queda bajo la tutela del Estado, y vinculado por una relación de especial sujeción, debe facilitar mecanismos adecuados para la consecución de este fin constitucional. De esta forma, mediante la inclusión de la reinserción como objetivo orientador se pretende, a través del encierro, la integración de la persona delincuente a la sociedad libre, una vez haya cumplido el tiempo previsto en la sentencia que le condena. Nuestra Constitución además incluye el término reeducación, junto al de reinserción, que en ocasiones ha sido criticado por la doctrina, dado que efectivamente puede llevar a confusión, que propone que se aluda únicamente al segundo "por su significado orientado a llevar una vida alejada del delito despojado de ideas moralizantes", que por el contrario sí puede contener de forma implícita el uso de la reeducación.

\footnotetext{
${ }^{3}$ Los fines de resocialización y reeducación se introducen en nuestro ordenamiento jurídico a través del art. 25.2 CE., que aporta los pilares básicos en los que se sustenta el Derecho penitenciario de la democracia.

${ }^{4}$ La prisión no surge para aplicar tratamiento alguno, ni reeducar, ni siquiera con intención de castigar al delincuente; la cárcel aparece como una manera de asegurar que el individuo que infringe las leyes no evada el castigo, suplicio o pena que se le haya impuesto, que generalmente solía ser la pena de muerte, galeras, algún tipo de mutilación o azotes. Ver FOUCAULT, M., Vigilar y castigar, Siglo veintiuno de España, Madrid, 1990, pp. 11 a 74.

${ }^{5}$ CERVELLÓ DONDERIS, V., Derecho penitenciario, Tirant lo Blanch, Valencia, 2001, p. 50.
} 
Apenas pasado un año, comienza la modificación y adaptación de la normativa penitenciaria a los nuevos vientos reformadores y democráticos ${ }^{6}$. Este novedoso ideal resocializador se traslada al acervo penitenciario, siendo el eje del mismo la LOGP, que alude a esta cuestión en su artículo primero ${ }^{7}$. Algunos autores consideran que la aprobación de esta ley fue una especie de prueba de la propia democracia ${ }^{8}$, que apenas estaba naciendo y dando sus primeros pasos.

Por consiguiente, se incluye en nuestro sistema penal y penitenciario el ambicioso y difícil objetivo de la reinserción en un momento en el que comenzaban a oírse voces críticas ante este ideal, y el escepticismo reinaba entre los estudiosos del Derecho 9 . Estas altas pretensiones han tenido como consecuencia que actualmente la prisión se haya convertido en una institución social con objetivos cada vez más complejos y contradictorios, ya que a raíz de esta nueva mentalidad la Administración penitenciaria ha tenido que asumir no solo la tradicional responsabilidad de proteger a la sociedad del delincuente, mediante el encierro y la vigilancia, además debe modificar la conducta y las actitudes de éste, así como favorecer su reintegración social ${ }^{10}$. Efectivamente son muchas las ocasiones en las que ambos retos entran en conflicto, dada su contradictoria naturaleza, puesto que el objetivo es conseguir que los reclusos adquieran un sentido de la responsabilidad en un medio donde incluso las actividades humanas más simples están reglamentadas y controladas ${ }^{11}$. De esta forma se pretende "combinar los fines de retribución y rehabilitación, a través de la privación de libertad y del tratamiento individualizado para conseguir un cambio del comportamiento antisocial”, ${ }^{\$ 2}$, es decir, supone querer reinsertar en la sociedad a una persona con los negativos condicionantes propios de la reclusión.

Pues bien, el instrumento utilizado por Instituciones penitenciarias para la consecución de este objetivo resocializador es lo que se conoce como tratamiento penitenciario. La LOGP separa y diferencia el régimen del tratamiento, y a pesar de que ambos tienen igualmente encomendada normativamente la misión de reinserción es éste último el que cumple esa función de forma directa. De hecho, el legislador ofrece una definición de régimen tomando el tratamiento como elemento teleológico, indicando que lo componen las reglas que pretenden crear una convivencia adecuada para conseguir un ambiente propicio con el fin de que el tratamiento penitenciario logre la finalidad marcada ${ }^{13}$. Además la normativa exige que ambos se coordinen adecuadamente, y en el supuesto de que exista un conflicto, éste debe resolverse a favor

\footnotetext{
${ }^{6}$ Sin embargo, la democratización, la inclusión $\mathrm{y}$, sobre todo, el asentamiento de las políticas humanitarias y resocializadoras no se produjeron con tanta celeridad ni de forma pacífica. Al contrario, esa etapa fue muy convulsa dentro de los muros de las prisiones. Para más información, ver LORENZO RUBIO, C., Cárceles en llamas, Virus, Barcelona, 2013.

${ }^{7}$ Art. 1 LOGP, siguiendo esta línea el RP insiste en esta finalidad: "La actividad penitenciaria tiene como fin primordial la reeducación y reinserción social de los sentenciados a penas y medidas de seguridad privativas de libertad, así como la retención y custodia de los detenidos, presos y penados y la asistencia social de los internos, liberados y de sus familiares".

${ }^{8}$ YAGÜE OLMO, C., Madres en prisión. Historia de las Cárceles de Mujeres a través de su vertiente maternal, Comares, Granada, 2007, pp. 130 y 131.

${ }^{9}$ CERVELLÓ DONDERIS, V., Derecho penitenciario, cit., p. 50.

${ }^{10}$ AYUSO, A., "La intervención socioeducativa", en Pedagogía Social. Revista Interuniversitaria, núm. 6-7, Diciembre 2000-Junio 2001, pp. 74 y 75.

${ }^{11}$ AYUSO, A., "La intervención socioeducativa", cit., p. 75.

${ }^{12}$ RODRÍGUEZ NÚÑEZ, A., "Prisión y derecho a la educación", en Anuario de la Escuela de Práctica Jurídica, núm. 1, 2006, p. 1.

${ }^{13}$ Art. 73 RP.
} 
del tratamiento, en base a la debida subordinación, prevista en la norma ${ }^{14}$, del régimen a éste $^{15}$.

La elección del vocablo "tratamiento" no ha estado exenta de crítica, al contrario, la doctrina ha entendido que el mismo "...tiene unas connotaciones desvalorativas de enorme significación. El delincuente aparece como un elemento negativo y disfuncional para el sistema social y el tratamiento es el crisol que produce el milagro de la readaptación" "16. Parece indicar que se trata de un enfermo que precisa de una cura que le será administrada a través de la prisión ${ }^{17}$, de esta forma el preso sería un paciente y el funcionario de prisiones se convertiría en personal sanitario. Al mismo tiempo, pudiera pensarse que el sistema penitenciario parte de la anormalidad del delincuente, concepto ya desfasado en Criminología.

Si el término usado ha suscitado controversia, el contenido también ha generado debate. La normativa no ha aportado demasiada claridad, de hecho la LOGP nos ofrece un concepto indicando de forma poco concreta que se trata del "conjunto de actividades directamente dirigidas a la consecución de la reeducación y reinserción social de los penados"18; y al mismo tiempo añade que la finalidad de esas actividades será "desarrollar en ellos una actitud de respeto a sí mismos y de responsabilidad individual y social con respecto a su familia, al prójimo y a la sociedad en general" "19. Además, al incluir la frase "en la medida de lo posible” parece que el legislador no confía demasiado en conseguirlo ${ }^{20}$.

Este poco agraciado término puede hacernos pensar que para esa transformación se requieren o se utilizan métodos exclusivamente médicos y sicológicos ${ }^{21}$. Precisamente a raíz del citado concepto normativo propuesto en el art. 59 LOGP, parece que el legislador pretende un tratamiento de índole sociológico-educativo, más que terapéutico o psicomédico. Además, en otros preceptos de la misma norma se puede esgrimir lo

\footnotetext{
${ }^{14}$ Art. 71.1 LOGP.

${ }^{15}$ Sin embargo, no sucede así en la práctica. Normalmente el tratamiento se define como las actividades que evitan los espacios aburrimiento, y lo importante es la seguridad y el régimen, CUTIÑO RAYA, S., "Algunos datos sobre la realidad del tratamiento en las prisiones españolas", en Revista Electrónica de Ciencia Penal y Criminología, núm. 17-11, 2015, p. 4: "En el mejor de los casos, se trata de una serie de actividades para mantener ocupadas por un tiempo a algunas personas reclusas, subordinándose siempre a las exigencias de seguridad y régimen”.

${ }^{16}$ MAPELli CAFFARENA, B., Lecciones de Derecho Penitenciario, Ice, Madrid, 1983, pp. 141 y ss.

17 De hecho, el Diccionario de la Real Academia Española define tratamiento como el "Conjunto de medios que se emplean para curar o aliviar una enfermedad”, por lo que la connotación negativa es clara y evidente.

${ }_{18}$ Art. 59 LOGP.

19 Art. 59 LOGP.

${ }^{20}$ RODRÍGUEZ NÚÑEZ, A., "Fórmulas para la resocialización del delincuente en la legislación y sistema penitenciario españoles", en http://www.uned.es/dpto-derecho-politico/arod.pdf, p. 20. (fecha de consulta 3 de mayo de 2016). Además, ante esta reflexión, sería preciso añadir que no sorprende la falta de confianza de la opinión pública respecto a la posibilidad de reinserción del sujeto delincuente. MUÑOZ CONDE, F., Derecho penal y control social, Fundación universitaria de Jerez, Jerez, 1985, p. 97.

${ }^{21}$ Como critica RODRÍGUEZ NÚÑEZ, A., "Fórmulas para la resocialización del delincuente en la legislación y sistema penitenciario españoles”, cit., p. 20.
} 
contrario, ya que parece impulsar y dar más importancia a la utilización de métodos más sicológicos ${ }^{22}$.

El RP otorga una mayor importancia a las actividades de carácter social y educativo, cuando indica en el preámbulo que las actividades terapéutico-asistenciales han de ser completadas con "actividades formativas, educativas, laborales, socioculturales, recreativas y deportivas, concibiendo la reinserción como un proceso de formación integral de su personalidad, dotándole de instrumentos eficientes para su propia emancipación”. Sin embargo, del texto se traduce que éstas actúan como complemento de la tradicional intervención sicológica, por lo que aunque este cambio se presenta como un avance será su posterior implementación lo que determinará si como tal debemos considerarlo.

Así pues, debemos partir de un concepto amplio y de carácter multidisciplinar en el que intervengan una pluralidad de profesionales con capacidad de ofrecer al interno recursos de diferente naturaleza e idóneos para que al salir de la prisión no reincida y se aleje del camino de la criminalidad. En este sentido, desde los profesionales de la educación social se "concibe el tratamiento desde un sentido amplio, como el conjunto de actividades de trabajo social, psicológico, educativo-escolar y cultura y de formación profesional que se pueden programar, realizar y evaluar en todos o en la mayoría de los establecimientos penitenciarios. En definitiva debe consistir en un modelo general aplicable en todos los establecimientos penitenciarios, y en modelos específicos dirigidos a grupos de internos con unos problemas o perfil determinados; como por ejemplo, jóvenes delincuentes, drogadictos, internos con problemas sicopatológicos, etc, ${ }^{23}$. Un tratamiento de índole sociológico busca la adaptabilidad social, por lo que es más difícil y complejo, pero el más adecuado y útil, siempre y cuando se tenga como límite el respeto a los derechos humanos, es decir, se debe exigir que se tenga en consideración los distintos modelos o sistemas de valores propios de una sociedad plural.

La importancia de la definición del tratamiento penitenciario no solo radica en reconocer el contenido y aclarar las pautas a seguir, también nos permite identificar a los profesionales encargados de su implementación. Y precisamente conocer la cualificación que se les exige, así como la ratio entre éstos y los presos, nos permite de forma más clara identificar la importancia que en realidad se le otorga a la reinserción de las personas privadas de libertad en un sistema penitenciario. De ahí que efectivamente incluso deban aparecer cuando se define el tratamiento penitenciario “...asimismo, esta concepción debe extenderse a todo los niveles del personal y a los diferentes especialistas que tienen que trabajar coordinadamente en la prisión"24.

Previo al análisis del personal encargado de la intervención penitenciaria, es preciso tener en cuenta, además de la definición de tratamiento, la evolución del mismo teniendo como marco el sistema sobre el que se sustenta. En este sentido se ha pasado

\footnotetext{
${ }^{22}$ En el art. 62 LOGP se desarrollan los principios del tratamiento, otorgando un papel relevante al diagnóstico sicomédico, convirtiéndolo en el eje del tratamiento y en la principal fuente de información.

${ }^{23}$ Por todos, CASTILlO AlgaRRA, J., y RUIZ GARCÍA, M., "Políticas penitenciarias para la inclusión de los prisioneros en España: tratamiento y rehabilitación social", en http://congreso.us.es/cesrea/OKpapers/Joaquina\%20Castillo\%20Algarra\%20Penitenciary.pdf (edición electrónica sin paginar).

${ }^{24}$ CASTILlO ALGARRA, J., y RUIZ GARCÍA, M., "Políticas penitenciarias para la inclusión de los prisioneros en España: tratamiento y rehabilitación social”, cit., (edición electrónica sin paginar).
} 
de un sistema progresivo al denominado de individualización científica. La diferencia entre ambos es que el primero es más rígido al aplicar criterios puramente objetivos en la clasificación penitenciaria del interno. Por el contrario, en la actualidad se ha evolucionado a un sistema que responde a criterios más subjetivos y flexibles, basados en la personalidad y las características del interno ${ }^{25}$. Al mismo tiempo, los términos individualización científica sugieren que se tratará a cada interno de forma particularizada, atendiendo a sus necesidades concretas, y además siguiendo los pasos propios de la intervención psicológica, médica, educativa y social. Por consiguiente, en la medida en que se debe tomar en consideración criterios subjetivos, se requerirá de personal cualificado con formación idónea para identificar los campos que precisan de atención e intervención especializada.

Efectivamente se trata de una actividad compleja que precisa de la coordinación de distintos profesionales que intervendrán cada uno en su campo. Por un lado, se pretende implementar un modelo que pueda recuperar al delincuente, mediante la denominada "Ciencia de la conducta", interviniendo directamente sobre el interno. Y, por otro lado, en la medida en que se parte de un horizonte amplio desde una acepción terapéutica a una social del tratamiento, también intervendrán otros profesionales, como educadores, animadores socioculturales o trabajadores sociales ${ }^{26}$.

Los funcionarios encargados del diseño e implementación del tratamiento son los miembros de la Junta de tratamiento ${ }^{27}$, tras el estudio de la personalidad del preso. Este órgano es el encargado de establecer los programas de tratamiento, así como de supervisar y controlar la ejecución de las actividades programadas, entre otras muchas funciones. Esta labor la realiza de forma específica el Equipo técnico de cada prisión que está conformado por profesionales de distintas áreas de la intervención penitenciaria integrados en las Juntas de tratamiento, convirtiéndose así en un grupo multidisciplinar capaz de ofrecer a los personas privadas de libertad durante el tiempo de condena, aquellas carencias que se hayan detectado en su ingreso a prisión ${ }^{28}$. Los profesionales que componen estos órganos, los denominados técnicos, son psicólogos, trabajadores sociales y educadores principalmente. Además hay que destacar la labor de las diferentes ONG y asociaciones privadas que desarrollan su labor asistencial en el interior de las prisiones ${ }^{29}$. En consecuencia, nos encontramos que una parte muy importante del tratamiento penitenciario, eje del cumplimiento de las penas privativas de libertad, está en manos privadas y conformada por grupos de voluntarios ${ }^{30}$.

\footnotetext{
${ }^{25}$ Arts. 72.1, 63 y 64 LOGP.

${ }^{26}$ HERRERO HERRERO, C., Criminología: Parte General y Especial, Dykinson, Madrid, 2001, pp. 46 y ss.

${ }^{27}$ Arts. 272 y ss. RP.

${ }^{28}$ El Equipo Técnico actúa bajo la dirección inmediata del Subdirector de Tratamiento, y podrán formar parte de él (nótese que el RP dice "podrán formar parte" y no "estará compuesto" como en el resto de órganos analizados) los siguientes profesionales: un Jurista; un Psicólogo; un Pedagogo; un Sociólogo; un Médico; un Ayudante Técnico; un Sanitario/Diplomado universitario en Enfermería; un Maestro o Encargado de Taller; un Educador; un Trabajador Social; un Monitor Sociocultural o Deportivo; y un Encargado de Departamento.

${ }^{29}$ Desde 2013 hay 749 ONG que colaboran en la ejecución de 979 programas. Información obtenida en la página web de Instituciones penitenciarias: http://www.institucionpenitenciaria.es/web/portal/Reeducacion/entidadesColaboradoras.html (fecha de consulta 2 de junio de 2016).

30 Instrucción 2/2012, sobre la intervención de organizaciones no gubernamentales, asociaciones y entidades colaboradoras en el ámbito penitenciario.
} 
En la lista de profesionales que compone el Equipo técnico se echa de menos la figura del criminólogo, como experto en el hecho y la conducta criminal, pues sería indudable su capacidad de aportar en la intervención específica del medio penitenciario. Si el Estado decide invertir en la creación de profesionales como los criminólogos, si además decide impulsar el cambio en la Universidad según los vientos europeos en los que se exige no sólo un Grado, además un Master, debe ofrecer a los criminólogos espacios en los que desarrollar la profesión para la que se han preparado. La necesidad de la Criminología en el ámbito penitenciario y la ausencia de profesionales con formación para realizar estos diagnósticos dan contenido a la reivindicación de un criminólogo en la Junta de tratamiento y el Equipo técnico ${ }^{31}$.

En este sentido, se debe tener presente, además, que el tratamiento es individual, es decir, se diseña para cada preso y se lleva a cabo mediante "un tratamiento individualizado que parte de un juicio de personalidad para programar actividades que consigan modificar el comportamiento del sujeto",32. Esto se traduce en que cada interno debe ser estudiado de forma particular, por lo que una labor de estas características precisa de una mayor inversión en profesionales cualificados para esta difícil tarea. Esta demanda no solo tendrá un carácter cualitativo, referido a la formación adecuada y suficiente, sino también cuantitativo, en el sentido de que deben ser suficientes.

La ratio de los profesionales que se dedican a la parcela tratamental es sensiblemente menor a la del cuerpo de ayudantes, dedicados a labores de vigilancia ${ }^{33}$. En la actualidad nos encontramos con diferentes quejas en cuanto a la falta de personal técnico en las plantillas, la carencia de sicólogos y trabajadores sociales suficientes es una demanda antigua, pero que en tiempos de crisis cobra especial relevancia ${ }^{34}$. Estos profesionales deben cumplir con una serie de obligaciones que, dado el número de presos que deben atender, resulta materialmente imposible que éstos reciban la atención que precisan, ya que a estos deberes debemos sumar aquellos de carácter administrativo, como elaborar informes, entre otros ${ }^{35}$. Además, la falta de material adecuado para desarrollar su labor

\footnotetext{
${ }^{31}$ BERNABEU AYELA, F.J., "El papel del criminólogo en prisión”, en CEREZO DOMÍNGUEZ A.I., y GARCÍA ESPAÑA E., (Coords.) La prisión en España una perspectiva criminológica, Comares, Granada, 2007, p. 249, este autor en estas páginas hace referencia a las funciones específicas del criminólogo en prisión. En el ámbito de los diagnósticos nos recuerda que “...el criminólogo es el experto en el estudio de los aspectos relacionados con el hecho criminal o con la conducta desviada”.

${ }^{32}$ RODRÍGUEZ NÚÑEZ, A., "Prisión y derecho a la educación", cit., p. 2, que abundando en esta cuestión indica que "no se trata de cambiar radicalmente el sentir o la forma de pensar de la persona, sino que, simplemente, deje de actuar en contra de los normas de convivencia que se ha dado la sociedad".

${ }^{33}$ CUTIÑO RAYA, S., "Algunos datos sobre la realidad del tratamiento en las prisiones españolas", cit., pp. 5 y ss., “De todo este personal, 24.925 personas, sólo 3.662 se dedican a tareas tratamentales o de asistencia (el 14,7\%), mientras que el cuerpo de ayudantes, destinado a las tareas de vigilancia, se compone de 19.363 personas, el 77,7\%. Particularmente grave es la situación en cuanto a juristas y psicólogos/as, siendo frecuente que haya uno o dos psicólogos/as para 500 o 600 personas internas, cuando se entiende que una proporción aceptable sería de una por cada cien. A esto se suma la sobreocupación de nuestros centros penitenciarios y la ingente tarea burocrática de los equipos destinados a las actividades tratamentales, lo que dificulta el contacto personal con la población reclusa y su efectiva intervención".

34 DEFENSOR DEL PUEBLO ANDALUZ, Informe especial al Parlamento: "Mujeres privadas de Libertad en Centros penitenciarios de Andalucía”, 2006, pp. 296 y ss.

${ }^{35}$ En este sentido resulta interesante traer las palabras de VALERO GARCÍA como Subdirector General de Tratamiento y Gestión penitenciaria, que denuncia que: "salvo contados casos de profesionales que utilizan parte de su tiempo de trabajo y algo más para realizar tratamiento, la mayoría no lo contempla, o no tiene tiempo o como no se lo exigen no lo ejerce. Los principales responsables no son los
} 
se ha convertido en otra queja habitual del personal técnico, que insisten en la necesidad de facilitar instrumentos de diferente naturaleza, como becas y ayudas para el estudio, o la posibilidad de acceso a internet, o la falta de ordenadores y otro tipo de materiales necesarios $^{36}$. En definitiva, la escasez de recursos humanos y materiales amerita una seria reflexión sobre la importancia que la sociedad otorga a la situación de las personas privadas de libertad y al verdadero interés institucional respecto al fin social de la reinserción.

\section{III.- ESTUDIO DE LOS PROGRAMAS Y LAS ACTIVIDADES TRATAMENTALES DESARROLLADAS EN LOS CENTROS PENITENCIARIOS}

Una vez hemos definido el tratamiento penitenciario e identificado a los profesionales garantes de su ejecución, debemos acercarnos a los programas y actividades que de forma concreta lo componen, y reflexionar en torno a su contenido y a su finalidad. De entre las actividades tratamentales podemos distinguir entre actividades sociológico-educativas, que son aquéllas que tienen un objetivo educativo, cultural, deportivo y ocupacional, por lo que efectivamente incidirán positivamente en la futura reinserción de las personas privadas de libertad, a pesar de su carácter generalista, y aquellos programas de intervención específica o actividades terapéuticoasistenciales, cuya función es ofrecer una respuesta a las carencias concretas y que requieren, por tanto, técnicas especializadas dentro del área terapéutica. Todas éstas a su vez podrán tener carácter prioritario o bien complementario atendiendo al "Programa Individualizado de Tratamiento",37 de la persona privada de libertad, que deberá reflejar de forma individual la función de cada una de ellas en el tratamiento de esa interna.

La regulación de las distintas modalidades de tratamiento en la normativa penitenciaria es desordenada y carece de una sistematización apropiada ${ }^{38}$. El legislador, en la LOGP, no menciona los posibles métodos de tratamiento, se limita a hacer una somera mención a la posibilidad de organizar sicoterapia de grupo, asesoramiento

profesionales, evidentemente, sino los dirigentes que se han entretenido en otros asuntos más cómodos, sin ninguna presión dada la suficiencia de plazas y el crecimiento lento y sostenido de la población (hasta que se produce la reforma de la Ley 7/2003), lo que ha permitido cierta tranquilidad y ninguna exigencia de resultados eficaces, lo único en lo que se mantiene ocupados a los profesionales es en la cantidad de informes que se les demandan. No hay ninguna iniciativa para promover, impulsar y realizar programas de tratamiento". VALERO GARCÍA, V., "El tratamiento penitenciario: realidad y perspectivas", en El juez de vigilancia penitenciaria y el Tratamiento penitenciario, Estudios de Derecho Judicial, CGPJ, 2006, pp. 30 y 31.

${ }^{36}$ CUTIÑO RAYA, S., "Algunos datos sobre la realidad del tratamiento en las prisiones españolas", cit., p. 6, "En los centros más antiguos es donde observamos más limitaciones, como patios muy pequeños, falta de instalaciones deportivas, insuficiencia de talleres y de materiales para las actividades, etc. Los centros más modernos están mejor dotados en infraestructuras y recursos materiales, aunque se ha perdido mucho en cuanto a trato humano, pues existe poco contacto directo entre personal y población reclusa. En cualquier caso, tanto en unos como en otros suelen existir problemas de habitabilidad, hacinamiento y deficiencias de mantenimiento". Posteriormente este autor critica que la crisis ha empeorado la situación.

37 También denominado PIT y la Instrucción 12/2006 los denomina también programas específicos de intervención. Instrucción 12/2006, sobre programación, evaluación e incentivación de actividades y programas de tratamiento. Protocolo de actuación para la programación, evaluación e incentivación de actividades y programas de tratamiento de los internos.

${ }^{38}$ Así lo denuncia CERVELLÓ DONDERIS, V., Derecho Penitenciario, cit., pp. 197 a 210. 
psicopedagógico y terapia de comportamiento ${ }^{39}$. Precisamente el contenido que en este precepto otorga el legislador al tratamiento penitenciario lo aleja del concepto social al hacer referencia a las ciencias conductuales de forma exclusiva.

El RP no ha sido tampoco muy explícito, aunque ha desarrollado las modalidades de tratamiento de forma más amplia que la LOGP, ya que al menos nombra específicamente las salidas programadas, los grupos en comunidad terapéutica, los programas de actuación especializada y la atención especializada en el exterior ${ }^{40}$. Así pues, vamos a partir de estos para observar si con ésta fórmula se consigue agrupar todo lo que se está implementando o por el contrario es importante adecuar la normativa a la realidad imperante dentro de los muros.

Las salidas programadas consisten en una actividad restringida al cumplimiento de una serie de requisitos ${ }^{41}$, como son estar clasificados en segundo o tercer grado, el cumplimiento de una cuarta parte de la condena y no observar mala conducta. El hecho de que estos coincidan con los permisos de salida no debería originar confusión entre ambas figuras. Aunque las dos tienen como función facilitar la consecución de la reinserción, los fines inmediatos son distintos ${ }^{42}$; ya que los permisos de salida preparan para la futura vida en libertad y las salidas programadas tienen como fundamento concretar o definir algún programa.

La misma Instrucción se hace eco de la capacidad reinsertadora de esta herramienta, cuando hace alusión específica a la admiración que otros países del entorno profesan por la misma ${ }^{43}$. Sin embargo, el desarrollo de esta actividad por parte de esta norma emanada del poder reglamentario de la Administración se hace en clave securitaria, otorgando un papel protagonista al desarrollo de las medidas de seguridad a pesar de que esta Instrucción se enmarca en el ámbito del tratamiento.

El temor a una posible evasión de la ejecución de la pena privativa de libertad es evidente, y esto se observa también en el número de presos que disfrutan de salidas programadas. En 2014 apenas 4041 presos fueron beneficiados por salidas programadas, esta cifra además está bajando cada año teniendo como punto álgido los años 2010 con 6925 y 2011 con 8913 beneficiarios, a partir de ahí cada vez son menos los internos que disfrutan de salidas programadas ${ }^{44}$. Estas cifras coinciden con el comienzo de la crisis, además, se dejan de convocar oposiciones y se dejan de subvencionar asociaciones. Por consiguiente, y teniendo en cuenta que es necesario dotarlas de profesionales que acompañen a los presos en esta actividad, se observa una clara relación entre las cifras no con un mero estancamiento sino con un descenso de más del $50 \%$ en menos de tres años.

\footnotetext{
${ }^{39}$ Las modalidades vienen reguladas en el art. 66 LOGP y, efectivamente, ofrece una visión superficial de las mismas.

${ }^{40}$ Ver arts. 114 a 117 RP. Ver, CERVELLÓ DONDERIS, V., Derecho Penitenciario, cit., pp. 197 a 210.

${ }^{41}$ Art. 114 RP

${ }^{42}$ No ayuda para una nítida distinción, al menos formalmente, el hecho de que ambas figuras se regulan en la misma Instrucción 1/2012.

La doctrina critica que ambas figuras vayan de la mano considerándolo desafortunado, entre otros, CERVELLÓ DONDERIS, v., Derecho Penitenciario, cit., p. 184.

${ }^{43}$ Instrucción 1/2012, pp. 16 y 17.

44 Informe $\quad$ General IIPP 2014 http://www.institucionpenitenciaria.es/web/export/sites/default/datos/descargables/publicaciones/Informe _General_2014_def_acc.pdf (fecha de consulta 25 de mayo de 2016).
} 
Los grupos en comunidad terapéutica, la siguiente actividad en ser mencionada por el legislador penitenciarista ${ }^{45}$, tienen un largo recorrido en nuestras prisiones, sobre todo en la intervención de adicciones ${ }^{46}$. Efectivamente se ha convertido en casi tradición encontrar un cuadro de adicción en las biografías de la mayor parte de los delincuentes, por lo que el tratamiento desintoxicador y deshabituador es una práctica habitual en las prisiones españolas. Además, mediante este tipo de intervención se cumple con el cometido de influir para cambiar las causas que llevaron al sujeto a cometer los delitos que le llevaron a prisión, acercándose de esta forma a la consecución de la reinserción.

Aunque existen muchas herramientas tratamentales que cumplen este fin, las comunidades terapéuticas se confirman como las más adecuadas y eficaces. El formato y la organización de estas comunidades han ido variando con el tiempo. En un principio teníamos los llamados "Módulos libres de Drogas", semilla de los actuales "Módulos UTE", que se conforman como unidades terapéuticas y educativas ${ }^{47}$. Estos módulos se organizan de forma similar a los de respeto, y están regulados por la Instrucción 9/2014, previamente ya se tuvieron en cuenta en la Instrucción $3 / 2011$, que venía a recoger las distintas estrategias que se estaban diseñando e implementando desde Instituciones penitenciarias en los distintos centros.

Esta herramienta es muy invasiva ya que tiene el objetivo de que la terapia este presente en todos los momentos de la vida de las personas presas, de esta forma "se pretende que las relaciones entre encarcelados y el personal de la institución sean similares a las existentes entre pacientes y enfermeros en un contexto terapéutico. El presupuesto teórico fundamental se sustenta en la creencia que ambientes institucionales profilácticos y participativos propiciarán un mayor equilibrio psicológico y la erradicación de la violencia, tanto dentro de la propia institución de custodia como en la vida en libertad"48. Por lo que el objetivo que se pretende es conseguir la deseada deshabituación y desintoxicación mediante una intervención ambiental, con la participación de un equipo multidisciplinar, incluyendo la colaboración del cuerpo de ayudantes, y los propios internos que forman parte del módulo.

Otro de los recursos tratamentales recogidos por el RP es la atención especializada en el exterior ${ }^{49}$. Esta herramienta se establece para los internos de segundo grado catalogados con baja peligrosidad social que no presenten riesgo de quebrantamiento de condena, por lo que se les ofrece la posibilidad de acudir a programas de atención especializada en instituciones del exterior.

La duración de cada salida no puede exceder de 8 horas diarias. En el supuesto de que éstas sean puntuales o tengan carácter irregular las autorizará el Centro Directivo,

\footnotetext{
${ }^{45}$ Art. 115 RP.

${ }^{46}$ No ha sido exclusivo para internos toxicómanos, también se ha utilizado en unidades de delincuentes violentos condenados a penas de larga duración, REDONDO ILLESCAS, S., "Psicología penitenciaria aplicada: los programas de rehabilitación en Europa", Ponencia en las I Jornadas de Tratamiento Penitenciario,

http://www.ub.edu/geav/contenidos/vinculos/publicaciones/public1_6/publicac_pdf/3_5\%20Redondo\%2 0Illescas, \%20S\%20(2000).pdf, Peñíscola, 2000, p. 6. (fecha de consulta 5 de mayo de 2016)

${ }^{47}$ Unidades Terapéuticas Educativas.

${ }^{48}$ REDONDO ILLESCAS, S., "Psicología penitenciaria aplicada: los programas de rehabilitación en Europa", cit., p. 6.

${ }^{49}$ Art. 116 RP.
} 
sin necesidad de autorización del Juez de Vigilancia Penitenciaria, que sí se precisa en el resto de supuestos. Muchos de estos programas se desarrollan en los Centros de inserción social que se suelen ubicar en las ciudades. Los beneficios que aportan desbordan los propios del contenido de la atención en concreto, ya que el hecho de permitir al interno salir del encierro aleja las nefastas consecuencias de la prisionización.

Por último, debemos analizar los programas de actuación especializada que, atendiendo a la literalidad del término, y previo al análisis, podemos deducir, que se trata de varios programas: bien porque se refiera a varios bien porque aún sin citar ninguno permita incluir futuros programas. Además porque el adjetivo especializada permite intuir que estos programas van dirigidos a remover las causas que determinaron la comisión del delito, o delitos, que tuvo como consecuencia la aplicación de una pena privativa de libertad.

La normativa penitenciaria recoge dos tipos de programas de actuación especializada ${ }^{50}$. Por un lado, se hace referencia al tratamiento de deshabituación dirigido a todos los internos con problemas de adicción ${ }^{51} \mathrm{y}$, por otro lado, se nombra, de forma genérica, un programa dirigido a los condenados por delitos contra la libertad sexual.

Como ya se ha comentado en líneas anteriores, la intervención en materia de adicciones tiene una larga trayectoria en prisión, tomando la institución conciencia de las consecuencias nefastas que éstas tienen para la salud del interno, y la imposibilidad obvia que genera de poder trabajar con ellos en ninguna otra área hasta que revierta esta situación. El tipo de intervención integrada en este apartado es menos invasivo que las comunidades terapéuticas y se diversifica, a su vez, en distintos programas como el intercambio de jeringuillas o el tratamiento con metadona. Para su puesta en práctica la Administración penitenciaria se coordinará con otras Administraciones públicas debidamente acreditadas, en el marco del Plan Nacional sobre drogas. Una de las características de esta acción es que va dirigida tanto a penados como a preventivos y no se hace distinción respecto a la situación procesal, todo sujeto encerrado que quiera participar podrá hacerlo.

Respecto al programa específico para delincuentes sexuales, está limitado a los condenados, por lo que no es posible que los preventivos puedan participar, ya que dada su naturaleza se conculcaría el principio de presunción de inocencia. El objetivo de los mismos es que "el delincuente sexual aprenda a reconocer situaciones de riesgo, aprenda a controlar sus impulsos, se conciencie del daño provocado a la víctima y asuma la responsabilidad y las consecuencias de sus actos ${ }^{32}$. El problema de estos programas es la falta de apoyo institucional cuando se van superando, ya que si a su desarrollo favorable no le sigue una política abierta de permisos de salida y progresión en la clasificación, los objetivos logrados pueden perderse ${ }^{53}$. Sin embargo, esa alarma social de la que son conscientes los técnicos integrantes de la Junta de tratamiento provoca que estos sean algo más cautelosos en la concesión de permisos de salidas o

\footnotetext{
${ }^{50}$ Art. 116 RP.

${ }^{51}$ Hay que distinguirlo de los grupos de comunidad terapéutica, pues aunque tengan el mismo fin se desarrollan de forma distinta.

${ }^{52}$ CUTIÑO RAYA, S., "Algunos datos sobre la realidad del tratamiento en las prisiones españolas", cit., p. 21.

53 Noticias como ésta provocan una alarma social que limita a las Juntas de tratamiento la concesión de esos permisos de salida: http://www.abc.es/hemeroteca/historico-24-10-2005/abc/Nacional/permisospara-violar-y-asesinar_611787824510.html
} 
progresión a tercer grado ${ }^{54}$. Efectivamente la sociedad se muestra incrédula, temerosa e inflexible respecto a la reinserción efectiva de este tipo de delincuentes, dado el temor y el reproche que generan particularmente los delitos sexuales, aunque las cifras presenten una alta tasa de reinserción, sobre todo tras la implementación de este programa ${ }^{55}$.

Estos dos son los que nombra la normativa de forma específica, a pesar de que cada vez se implementan más programas ${ }^{56}$, entre ellos se encuentran algunos de naturaleza similar al existente dirigido a delincuentes sexuales, como son los de violencia de género ${ }^{57}$ o los dirigidos a la educación en el ámbito de la seguridad vial. Estos dos programas, junto al anterior sobre criminalidad sexual, tienen en común que se desarrolla a través de ellos una intervención que atiende de forma directa a la naturaleza del delito que cometió el sujeto. De ahí que no puedan participar en ninguno de ellos los presos preventivos, y solo los condenados puedan hacerlo.

Al mismo tiempo, se desarrollan otros programas específicos que, si bien no atienden a la naturaleza del delito, sí a las posibles causas que determinaron la comisión del mismo y la entrada en prisión. Como son los programas para extranjeros y los dirigidos a la mujer privada de libertad, dirigidos a una población especialmente vulnerable a la discriminación o a ser utilizados por otros sujetos para la perpetración de los delitos que los han llevado a cumplir condena. Estos programas tendrían una naturaleza similar a la educación y al trabajo, tienen capacidad integradora en la sociedad libre porque ofrecen una alternativa a estas personas, y se diferencian de estos porque no son generales, no van dirigidos a todas las personas privadas de libertad, se orientan a las necesidades específicas de estos grupos especialmente vulnerables.

\footnotetext{
54 "El penado cumple condena a ocho años y ocho meses de prisión por delito de abusos sexuales. En este tipo de delitos, en razón de la psicología del agresor y la dificultad de control de impulsos, suele ser frecuente la reincidencia, conforme a reglas de experiencia. Esa peligrosidad, ya demostrada, y que puede dar lugar a nuevos delitos ha de disminuir para poder dar lugar a los permisos. La mejor forma es seguir algún programa específico en relación con los delitos cometidos. Alternativamente puede confiarse en el efecto preventivo especial de la pena, al menos en su dimensión intimidativa. No existen datos de lo primero, y en cuanto a lo segundo el interno no ha cumplido la tercera parte de la condena, con lo que mal puede haberse dado tal efecto. Se desestimará el recurso". Así, el Auto Juzgado de Vigilancia Penitenciaria 3 Madrid 822/12, de 28 febrero. Por otro lado, la sentencia de la Audiencia Provincial de Madrid 22 de julio 2003, acepta la progresión a tercer grado, acompañada de la participación en un programa de tratamiento específico para mejorar la educación sentimental y sexual del sujeto.
}

${ }^{55}$ REDONDO ILLESCAS, S., SÁNCHEZ MECA, J., GARRIDO GENOVÉS, V., "Los programas sicológicos con delincuentes: la situación europea", en Psicothema Revista anual de Psicología, vol. 14, 2002, p. 171.

${ }^{56}$ En la lista facilitada por Instituciones penitenciarias se integran los siguientes programas: Agresores sexuales - Alcoholismo - Discapacitados - Drogodependencia - Enfermos mentales - Jóvenes - Juego patológico - Madres - Módulos de respeto - Módulos terapéuticos - Mujeres - Personas extranjeras Preparación de permisos de salida - Prevención de suicidios - Programa de régimen cerrado - Resolución dialogada de conflictos - Seguridad Vial - Tabaquismo - Terapia asistida con animales - Violencia de genero.

Fuente:

Instituciones

penitenciarias

http://www.institucionpenitenciaria.es/web/portal/Reeducacion/ProgramasEspecificos/ (Fecha de consulta 25 de mayo de 2016).

${ }^{57}$ Violencia de género: se trata de un programa especial para este tipo de delincuencia que se crea en 2001. 
La población extranjera en prisión se ha visto incrementada en los últimos años, y ya se preveía en algún articulado del RP cómo se iba a organizar su estancia en prisión atendiendo a las particularidades que pueden presentar ${ }^{58}$. Los programas de extranjería en las prisiones españolas tienen una finalidad eminentemente educativa siempre con un trasfondo integrador, en el que prime la multiculturalidad y el respeto por la cultura propia del interno extranjero ${ }^{59}$. Este programa tiene tres ejes fundamentales: Programa de idiomas y educación primaria, Programa de formación multicultural y Educación en valores y habilidades cognitivas. Por ende nos encontramos con dos objetivos "facilitar su integración en el medio penitenciario y, finalmente, en la sociedad ${ }^{\prime 60}$.

La existencia de un programa de estas características sería valorado positivamente si fuese acompañado de otras políticas penales y penitenciarias de similar naturaleza integradora, sin embargo, la política criminal en materia de ejecución de la pena privativa de libertad del extranjero condenado está muy lejos de ese ideal integrador, como se evidencia en la última reforma del art. 89 del Código penal ${ }^{61}$. De manera que, resulta contradictorio que por un lado se trabaje con ellos para conseguir su integración y por otro se les muestre la puerta de salida del país, de ahí que estas reformas puedan generar que los técnicos en prisión se encuentren con sujetos poco participativos y sin motivación. Por lo que realmente apenas tiene capacidad para cumplir el primer objetivo, integrar en el medio penitenciario al interno extranjero.

Respecto a la mujer en prisión, la gran olvidada, hay que indicar que tradicionalmente no se han previsto actividades o programas que atiendan a las peculiaridades o necesidades de la mujer delincuente privada de libertad ${ }^{62}$. La doctrina critica que las ofertas, tanto formativas como laborales dentro de la prisión, no aportan nada nuevo a la mujer ${ }^{63}$. Sin embargo, la Administración penitenciaria parece que

\footnotetext{
${ }^{58}$ Los arts. 15 y 52 RP hacen referencia a derechos y obligaciones, el art. 49 RP hace referencia a las comunicaciones y de forma específica a las que pueden realizar con sus representantes diplomáticos, $\mathrm{y}$ otros como el 118 o 123 hacen referencia a la necesidad de que aprendan el idioma priorizando estos cursos en la educación reglada.

59 "En septiembre de 2005, se remitió a los Centros penitenciarios el "plan marco de intervención educativa con internos extranjeros" presentado por la comisión citada. Contiene tres programas específicos con carácter flexible y abierto y con técnicas y actividades diversas, pero con la misma finalidad. Su finalidad es contribuir al desarrollo personal y a la integración de los internos extranjeros en una sociedad democrática, tolerante y pacífica, así como facilitar la convivencia ordenada en prisión, creando espacios de entendimiento en las relaciones interpersonales", GARCÍA GARCÍA, J., "Extranjeros en prisión; aspectos normativos y de intervención penitenciaria", en Derecho penitenciario.com http://www.derechopenitenciario.com/comun/fichero.asp?id=1333, pág. 21 (fecha de consulta 27 de mayo de 2016).

${ }^{60}$ CUTIÑO RAYA, S., "Algunos datos sobre la realidad del tratamiento en las prisiones españolas", cit., p. 29.

${ }^{61}$ Este precepto reformado por la LO 1/2015 se conforma como el eje de una política basada en la expulsión del ciudadano extranjero.

${ }^{62}$ GALLARDO GARCÍA, R.M., "Tratamiento penitenciario: la necesario orientación de género" en ACALE SÁNCHEZ, M., y GÓMEZ LÓPEZ R., (Coords.) Derecho penal, género y nacionalidad, Comares, Granada, 2015, pp. 218 y ss.

${ }^{63}$ En línea similar, denunciando que las mujeres no tienen acceso, o lo tienen limitado, a la formación en el empleo de profesiones de alta insertabilidad, AGUADO CORREA, T., "Dimensión de género en las políticas y centros penitenciarios", en MAPELLI CAFFARENA, B., SORDI STOCK, B., AGUADO CORREA, T., HERRERA MORENO, M., GUTIÉRREZ MORENO, F.M., Mujeres en las cárceles de Andalucía, Dyckinson, 2012, p. 352. De hecho, "la cárcel pasa a ser el lugar privilegiado para recordar y enseñar a las mujeres que son y han de seguir siendo buenas hijas, esposas o madres. Ni que decir tiene que si la resocialización significa enseñar aquello que no se sabe, aquello necesario para reintegrarse en la sociedad, parece irónico pensar que las presas no saben ser madres, esposas, amas de casa y que
} 
comienza a ser consciente de su presencia en las prisiones y de las necesidades que éstas demandan, y ha comenzado a desarrollar programas configurados para ellas. En este sentido, debemos destacar el "Programa de Acciones para la Igualdad entre Mujeres y Hombres en el ámbito penitenciario" que se ha venido implementando desde el año $2009^{64}$. Hasta este momento, no se había impulsado una estrategia general penitenciaria de género ni se habían implementado programas específicos generales dirigidos a ellas.

A raíz de este Plan, debemos hacer referencia, dada su importancia en la intervención penitenciaria, a la creación y desarrollo del programa "sermujer.es". La razón de ser de un proyecto de estas características es que se ha evidenciado que existe un elevado número de mujeres presas que han sido o son víctimas de violencia de género $^{65}$. Uno de los aspectos que mayor interés despierta este programa es que incide no en el delito que las llevó al cumplimiento de esa pena privativa de libertad, sino a las posibles razones que las llevó a cometer el delito.

Los programas que hasta ahora hemos analizado tienen como objetivo intervenir en las causas directas que llevaron al sujeto a cometer el delito, como son los primeros, y aquellos que lo hacen en las causas que indirectamente pudieron motivar al sujeto a cometerlos, como son los específicos para grupos vulnerables. No existe ningún otro programa de similares características que intervenga de forma directa atendiendo a otro tipo de delincuencia, que igualmente podamos encontrarnos en el interior de las prisiones, como la corrupción, la de cuello blanco o la desarrollada por organizaciones criminales, entre otras. De hecho, llama la atención que los pobladores de las prisiones provenientes de delincuencia vinculada a la corrupción no tengan un programa específico por lo que es preciso en que se adapten los contenidos de los programas y actividades a sus necesidades tratamentales. La ausencia de estos programas evidencia una laguna importante y a tener en cuenta, dado que no estamos ante un tipo de criminalidad nueva, por el contrario, estamos ante un tipo de delincuencia tradicional, aunque es cierto que, bien por la vía de la suspensión bien por la del indulto, pocos entran en prisión. Sin embargo, la preocupación social que han suscitado estos delitos precisa de una respuesta por parte de Instituciones penitenciarias.

En un tercer grupo integramos los programas que más bien tienen como fin mejorar el clima en la prisión y la adaptación al medio penitenciario, haciendo que la vida del interno sea más fácil. La afirmación anterior no niega la capacidad reinsertadora de estas herramientas, de hecho incluso el régimen tal y como ha sido configurado en la normativa penitenciaria tiene esa finalidad de reeducación. Entre estos programas nos podemos encontrar, los programas de prevención de suicidios, la atención a discapacitados y enfermos mentales, el específico de los módulos cerrados y, por supuesto, el programa estrella de todas las prisiones, el módulo de respeto.

precisamente, esto es lo que necesitan saber para reinsertarse en la sociedad", ALMEDA SAMARANCH, E., "Pasado y presente de las cárceles femeninas en España", en Revista de pensamiento sociológico, núm. 6, 2005-06, p. 101.

${ }^{64}$ Respecto a los contenidos debemos destacar los siguientes puntos: actuaciones a nivel organizativo; observatorio permanente para la erradicación de factores de discriminación basados en el género; atención integral a las necesidades de las mujeres encarceladas y excarceladas; planes para favorecer la erradicación de la violencia de género y paliar sus consecuencias.

${ }^{65}$ Esta evidencia se constata a nivel internacional: Reglas de Bangkok núm. 60. También la doctrina española hace referencia al gran número de mujeres presas que han sufrido violencia y abusos sexuales, no solo antes de su entrada en prisión, también durante la misma, AGUADO CORREA, T., "Dimensión de género en las políticas y centros penitenciarios", cit., p. 337. 
La prisión tiene entre sus pobladores un elevado número de internos que padece algún tipo de enfermedad o trastorno mental ${ }^{66}$, y bastante menos con algún tipo de discapacidad $^{67}$. De estos dos programas el más implementado es el referido a los internos que padecen trastorno o enfermedad mental y "tiene tres líneas de actuación: detección del caso y atención clínica, programa de rehabilitación individualizado y ayuda a la incorporación social" ${ }^{\text {68 }}$. Y a pesar de que la reinserción aparece como objetivo las herramientas para su consecución se restringen al medio penitenciario y "al no existir ninguna coordinación con los servicios sociales y no trabajar el regreso a la sociedad y a la propia familia y al no disponer muchas de las personas con enfermedad mental de apoyo familiar ni respaldo económico, la consecuencia más habitual sea que retornen a un submundo marginal y de subsistencia en la calle y no sigan ningún tipo de tratamiento o medicación" ${ }^{69}$. No solo su escasa capacidad reinsertadora ha ubicado en este apartado este programa, también el hecho de que la prisión está asumiendo cada vez más el papel que otrora tuvieren los antiguos siquiátricos.

El referido a la prevención de suicidios comienza cuando se evidencia un alto número de suicidios. Se desarrolla a través del acompañamiento continuo de otro preso que cuida de que su estancia sea más fácil y menos traumática, y no lo vigila continuamente para evitar situaciones de riesgo. Este es uno de los programas en el que se cuestiona de forma más clara que persiga el objetivo reinsertador encomendado "...pues no se trata de un programa estrictamente resocializador, aunque es imprescindible en un lugar que se dedique a la recuperación social de las personas" "70.

El programa específico de los módulos cerrados se dirige a los presos clasificados en primer grado dedicado a internos extremadamente peligrosos o manifiestamente inadaptados. Este programa tiene como finalidad solucionar una laguna evidenciada, referida a la ausencia de tratamiento específico para este perfil de internos ${ }^{71}$. Y aunque la intervención en este grado obviamente puede repercutir en la reinserción, realmente en la mayor parte de los objetivos marcados se hace referencia a la progresión a segundo grado y su adaptación al medio penitenciario, por lo que se trata de mejorar su situación penitenciaria ${ }^{72}$.

\footnotetext{
${ }^{66}$ En el año 2010 se ha finalizado la redacción del Protocolo de Atención Integral al Enfermo Mental (PAIEM).

${ }^{67}$ El Programa de Discapacitados se realiza desde el año 1995 en colaboración con la Confederación Nacional de Organizaciones a favor de las personas con discapacidad intelectual (FEAPS).

${ }^{68}$ CUTIÑO RAYA, S., "Algunos datos sobre la realidad del tratamiento en las prisiones españolas", cit., p. 32 .

${ }^{69}$ CUTIÑO RAYA, S., "Algunos datos sobre la realidad del tratamiento en las prisiones españolas", cit., p. 33 .

${ }^{70}$ CUTIÑO RAYA, S., "Algunos datos sobre la realidad del tratamiento en las prisiones españolas", cit., p. 28.

${ }_{71}$ Sentencia del Tribunal Constitucional de 8 de julio de 1996, sobre la falta de orientación a la reinserción de la estancia en prisión de los primeros grados: "este principio (el de resocialización) no genera un derecho subjetivo a que cada aspecto de la organización de la vida en prisión se rija exclusivamente por el mismo, con independencia del también fin primordial de las Instituciones Penitenciarias de retención y custodia de detenidos, presos y penados que comporta garantizar y velar por la seguridad y el buen orden regimental del Centro. Este último objetivo es el que expresamente persiguen las restricciones a las que se atribuye su nula orientación hacia la reeducación, con patente desconocimiento de la carencia de exclusividad de este fin en la ejecución de la pena privativa de libertad".

${ }^{72}$ Circular $7 / 2011$.
} 
Cabe destacar los módulos de respeto que representan una concepción menos punitiva de la prisión y más educativa. La denunciada falta de personal suficiente en general, tanto en intervención como vigilancia, ha provocado que se hayan formulado programas que precisan de una menor intervención y participación de funcionarios, y sobre todo una menor presencia de estos en el módulo ${ }^{73}$. Los presos se encargan de la organización y control de la mayor parte de las actividades que se desarrollan en estos módulos. Estos módulos se han integrado y popularizado en el sistema penitenciario español a través de la económica fórmula de las buenas prácticas. Se desarrollan tres niveles de exigencia atendiendo al perfil del interno ${ }^{74}$, pero las carencias de un marco pedagógico adecuado suponen una crítica a tener en cuenta, ya que esa es la forma de aproximación a que "...los objetivos de reeducación sean asumidos con los planteamientos pedagógicos que se están trabajando en la sociedad actual y hacer normal en la cárcel lo que educativamente es normal en la sociedad" ${ }^{\text {75. }}$.

En definitiva, efectivamente se confirma que el tratamiento ha ido evolucionando con el paso de los años, y en estos cambios han participado las nuevas estructuras arquitectónicas como las macrocárceles, la falta de personal suficiente, la mayor conexión que internet proporciona a los profesionales, los nuevos tipos de criminalidad, entre otros factores. Por consiguiente, una vez hemos comprobado que efectivamente existe una serie de ventajas que amerita la reforma de las dos leyes fundamentales del acervo penitenciario, LOGP y RP, debemos concretar y justificar qué contenido debe integrar esta reforma y la finalidad que cumpliría cada uno.

\section{IV.- LA NECESARIA REFORMA LEGISLATIVA EN EL ÁMBITO DE LOS PROGRAMAS DE TRATAMIENTO}

La LOGP obtuvo grandes alabanzas por parte de la doctrina tras su aprobación, siendo calificada como moderna, en el sentido de apropiada para el sistema político que se estaba gestando, el paso necesario para el canto democrático que por entonces se comenzaba a entonar. Sin embargo, aún se sigue usando mecánicamente ese adjetivo, por lo que es el momento de que se haga honor al mismo y evolucione adaptándose a los nuevos tiempos. El acervo prevencionista apenas ha sido reformado en los últimos años y menos aún en un ámbito tan relevante como es el tratamiento penitenciario ${ }^{76}$. Y en esos primeros años cualquier modificación respecto del régimen anterior, en cuanto efectivamente suponía un cambio, era valorada positivamente, pero en estos tiempos las

\footnotetext{
${ }^{73}$ La propia Instrucción que los regula hace referencia a que los funcionarios de prisión son los principales valedores de este sistema porque han potenciado un ambiente más relajado y han mejorado la relación funcionario-preso; ver Instrucción 18/2011, p. 3. El hecho de que se esté en tiempos de crisis económica, dada la falta de funcionarios, ha supuesto que se haya convertido en una herramienta ampliamente implementada en todos los centros penitenciarios del país. Además esta Instrucción hace referencia a que el objetivo es mejorar la convivencia, p. 4.

${ }^{74}$ Instrucción $18 / 2011$, p. 6, indica que no existe un perfil concreto y que se atenderá a diferentes variables.

${ }^{75}$ VALDERRAMA BARES, P., "Los módulos de respeto en las cárceles, una revisión desde la educación social”, en Revista de Educación Social, núm. 22, enero 2016, p. 20. Además deberíamos añadir a esta crítica la falta de exigencia de cualificación a los educadores en prisión.

${ }^{76}$ En este ámbito, el trabajo penitenciario es una excepción. Hace poco fue reformado el estatuto de la entidad de trabajo público y formación para el empleo, que está regulado por el Real Decreto 122/2015, de 27 de febrero. Un análisis de esta reforma y de la necesidad de otras en esta compleja materia nos obliga a excluirlo de estas páginas, como ya se hizo referencia.
} 
necesidades son diferentes, por lo que los niveles de exigencia deben igualmente ser diferentes.

Dada la relevancia práctica del tratamiento penitenciario en los sistemas penitenciarios es obvio que la necesidad de reforma se torna perentoria. El contenido de la LOGP y del RP es excesivamente parco, como hemos podido comprobar, por lo que si la sociedad ha evolucionado el sistema penitenciario debe igualmente evolucionar, $\mathrm{y}$ las herramientas que en otros tiempos supusieron un hito ahora han quedado desfasadas.

Esta parquedad en ambas normas ha repercutido en un mayor desarrollo de las actividades y programas penitenciarios vía potestad reglamentaria de la Administración penitenciaria, mediante instrucciones y circulares. Esta normativa de carácter reglamentario posee determinados atributos que la hacen adecuada para la organización y desarrollo de determinadas funciones penitenciarias. Efectivamente, el dinamismo que se les atribuye las convierte en una herramienta idónea en ámbitos que precisan una rápida adaptación a los cambios. Sin embargo, a pesar de que Instituciones penitenciarias posea la herramienta adecuada o idónea continúa siendo actual la crítica de que esta Administración es excesivamente lenta antes los cambios que requiere el tratamiento penitenciario ${ }^{77}$. Por consiguiente, aunque el vehículo sea adecuado la falta de interés por parte de la Administración en adaptarse sigue siendo, entre otros factores, el mayor de los problemas.

Así mismo, cabe señalar que la mayor crítica que reciben las instrucciones y circulares es su permeabilidad política. Una aproximación a las instrucciones penitenciarias te permite observar las distintas variaciones atendiendo a la ideología política de quien ostenta la Secretaría General. Por tanto, algunas cuestiones deberían ubicarse en una norma de rango superior con un mayor y mejor control parlamentario y que atienda a las demandas de consenso y pluralidad social, puesto que dada la importancia de la materia sería aconsejable que se utilizaran mecanismos menos intoxicados evitando la manipulación política y partidista.

Por otro lado, obras como la "Naranja mecánica" pusieron de manifiesto a la sociedad la capacidad que tiene el ser humano de dañar bajo la excusa del tratamiento penitenciario. La realidad nos muestra cómo la reinserción como rehabilitación puede ser la excusa para el uso de técnicas cercanas a la reprogramación tan alejadas de los principios democráticos propios de un Estado de Derecho ${ }^{78}$. Así pues, la reticencia mostrada por la doctrina por el uso de términos como la reeducación o rehabilitación dejan de ser una cuestión estética para convertirse en el discurso adecuado para la consecución de esos fines garantistas en el sistema penitenciario.

En la medida en que existen nuevas técnicas tratamentales, éstas deben ser evaluadas para determinar si efectivamente son de carácter invasivo y confunden tratamiento penitenciario con la idea de reprogramación, anulando al individuo. De ahí la necesidad de que la normativa penitenciaria sea más precisa, ya que la declaración de principios o

\footnotetext{
${ }^{77}$ Un ejemplo que ratifica esta afirmación lo encontramos en la lentitud en la implementación de los programas de jeringuillas, que cuando empezaron a desarrollarse ya había cambiado la forma de consumo; también en otro ámbito como la necesidad de internet como herramienta de estudio o forma de comunicación, que sigue sin ofrecer una respuesta satisfactoria.

${ }^{78}$ Ejemplo actual de ello lo vemos en Guantánamo.
} 
la proclamación de la vigencia de los derechos humanos dentro de las prisiones no siempre es suficiente.

Salvando las cuestiones éticas, indiscutiblemente las soluciones a los problemas, tanto públicos como privados, precisan de un estudio previo de la idiosincrasia de los mismos. Y precisamente en esta fase nos encontramos con el siguiente factor que provoca discriminación o ausencia de una respuesta adecuada: existe un importante desconocimiento de las características sociales y criminológicas del heterogéneo y abultado grupo de personas que cumplen condena; a mencionar, las mujeres delincuentes, el yihadismo o la corrupción, entre otros.

Conforme a esto, obviamente el medio penitenciario no es ajeno a la necesidad de explicar y comprender en profundidad los problemas que acontecen a su población no solo atendiendo a la praxis, sino desde modelos teóricos adecuados ${ }^{79}$. No podemos obviar una premisa básica: cualquier intervención requiere de una previa investigación. Sin embargo, "...la labor investigadora ha venido estando tan al margen del profesional de la intervención, como la labor de intervención del profesional de la investigación" "si no caminamos en esa dirección, la investigación seguirá funcionando al margen de la realidad del fenómeno, desde una confortable pero ineficaz distancia, y la intervención funcionará a unos niveles meramente tentativos, voluntarista o simplemente lógica ${ }^{\text {} 81}$.

Así pues, dada la relevancia del tratamiento en el sistema penitenciario no son pocas las voces en la doctrina que denuncian la necesidad de actualizar los contenidos de las diferentes actividades y programas de tratamiento que se desarrollan dentro de las prisiones $^{82}$. El hecho de la que la normativa plasme estas innovaciones en el área tratamental supondría una serie de ventajas a tener en cuenta. En este sentido destaca, en primer lugar, la mayor visibilización de los contenidos de la herramienta que cumple la difícil función de la reinserción, lo que aportaría mayor seguridad jurídica. De esta forma, los abogados y otros profesionales, incluso los voluntarios, que trabajan en el medio penitenciario conocerían mejor el contenido, dada la importancia que se le otorga para la obtención de determinados beneficios penitenciarios. Además, estas leyes tienen mayor poder vinculante, aportando a todos los internos esa debida igualdad de oportunidades, o la posibilidad de denunciarla, mediante la homogenización de las

\footnotetext{
${ }^{79}$ En el ámbito de la necesaria orientación de género: la producción científica en Criminología se ha centrado en el análisis de muestras de hombres, de forma que la delincuencia femenina ha sido invisibilizada o incluso negada, en la medida en que las explicaciones de la delincuencia de las mujeres simplemente se extrapolaban a partir de modelos teóricos validados con muestras masculinas. Así pues, la llamada ceguera de género ha sido una constante para los investigadores, "las escasas investigaciones realizadas durante el siglo XIX y la primera mitad del XX tendían a aplicar teorías biológicas y psicológicas para explicar la criminalidad femenina y resaltaban el hecho de que, en todos los lugares en los que se había estudiado el tema, la participación de los hombres era ampliamente mayoritaria", FULLER, N., "La perspectiva de género y la criminología: una relación prolífica", en Tabula Rasa. Bogotá - Colombia, núm. 8: 97-110, enero-junio 2008, p. 100.

${ }^{80}$ VARELA, J., "La situación de las cárceles y la intervención en el contexto penitenciario", en ÁLVAREZ URÍA, F., (Ed.) Marginación e inserción, Endymion, Madrid, 1992, pp. 313 y ss.

${ }^{81}$ VARELA, J., "La situación de las cárceles y la intervención en el contexto penitenciario", cit., pp. 313 y ss.

${ }_{82}$ Por todos, BUENO ARÚS, F. "Novedades en el concepto de tratamiento penitenciario", en Revistas de estudios penitenciarios, núm. 252, 2006, pp. 9 a 36.
} 
mismas en todos los centros penitenciarios sin excepción, evitando lo que se denomina las cárceles castigo.

Pero la principal ventaja es que la actual regulación presenta déficits de contenidos, ya que desde que se aprobó esta materia ha evolucionado cuantitativa y cualitativamente. Además es preciso concretar qué criterio debe seguirse para incluirlos en la LOGP o el RP, y en este sentido debe ser, al menos, que se introduzcan las herramientas que ya están implementadas en nuestro sistema penitenciario porque ya se ha mostrado su necesidad y evaluado su funcionalidad. Y siendo más exigentes, que se incluyan aquéllas que ofrecen ventajas y aportarían beneficios si fuesen implementadas. A su vez, sería de gran importancia que se tuviera presente en este proceso que estos mecanismos son de reinserción para que los presos puedan vivir sin delinquir cuando salgan de la prisión, no para sobrevivir al medio penitenciario, tampoco para solucionar los problemas de falta de personal.

En definitiva, el tratamiento penitenciario tiene la complicada misión de cumplir el mandato constitucional de reeducar y de resocializar las personas que cumplen una pena privativa de libertad, que no es más que prepararlas para el momento de su salida de prisión y posterior incorporación en la sociedad libre, sin que vuelvan a cometer más delitos, evitando, por tanto, la reincidencia. Aunque esta afirmación de nuevo nos vuelve a enfrentar con otra traba puesto que sería ideal tener un modelo de referencia ${ }^{83}$, es decir, determinar en qué tipo de sociedad queremos reinsertar a las personas teniendo en cuenta que nos movemos en sistemas normativos en ocasiones contradictorios ${ }^{84}$. En principio la reforma no debe resultar complicada solo se trata de incluir los modelos que llevan tiempo incorporados en el sistema penitenciario, poniendo de relieve, y esto presenta mayor dificultad, cuáles de ellos van dirigidos a la reinserción y cuáles se limitan a conseguir una adaptación al medio penitenciario.

\section{BIBLIOGRAFÍA}

AGUADO CORREA, T., "Dimensión de género en las políticas y centros penitenciarios", en MAPELLI CAFFARENA, B., SORDI STOCK, B., AGUADO CORREA, T., HERRERA MORENO, M., GUTIÉRREZ MORENO, F.M., Mujeres en las cárceles de Andalucía, Dyckinson, 2012.

ALMEDA SAMARANCH, E., "Pasado y presente de las cárceles femeninas en España”, en Revista de pensamiento sociológico, núm. 6, 2005-06.

AYUSO, A., "La intervención socioeducativa", en Pedagogía Social. Revista Interuniversitaria, núm. 6-7, Diciembre 2000-Junio 2001.

BERNABEU AYELA, F.J., "El papel del criminólogo en prisión", en CEREZO DOMÍNGUEZ A.I., y GARCÍA ESPAÑA E., (Coords.) La prisión en España una perspectiva criminológica, Comares, Granada, 2007.

\footnotetext{
${ }^{83}$ CERVELLÓ DONDERIS, V., Derecho penitenciario, cit., p. 51.

${ }^{84}$ GARCÍA PABLOS DE MOLINA, A., "La supuesta función resocializadora del Derecho penal: utopía, mito, y eufemismo", en Anuario de Derecho penal y Ciencias penales, 1979, p. 678.
} 
CASTILlO ALGARRA, J., y RUIZ GARCÍA, M., "Políticas penitenciarias para la inclusión de los prisioneros en España: tratamiento y rehabilitación social", en http://congreso.us.es/cesrea/OKpapers/Joaquina\%20Castillo\%20Algarra\%20Penitenciar y.pdf

CERVELLÓ DONDERIS, V., Derecho penitenciario, Tirant lo Blanch, Valencia, 2001.

CUTIÑO RAYA, S., "Algunos datos sobre la realidad del tratamiento en las prisiones españolas", en Revista Electrónica de Ciencia Penal y Criminología, núm. 17-11, 2015. DEFENSOR DEL PUEBLO ANDALUZ, Informe especial al Parlamento: "Mujeres privadas de Libertad en Centros penitenciarios de Andalucía", 2006.

FOUCAULT, M., Vigilar y castigar, Siglo veintiuno de España, Madrid, 1990.

FULLER, N., "La perspectiva de género y la criminología: una relación prolífica", en Tabula Rasa. Bogotá - Colombia, núm. 8: 97-110, enero-junio 2008.

GALLARDO GARCÍA, R.M., "Tratamiento penitenciario: la necesaria orientación de género" en ACALE SÁNCHEZ, M., y GÓMEZ LÓPEZ R., (Coords.) Derecho penal, género y nacionalidad, Comares, Granada, 2015.

GARCÍA GARCÍA, J., "Extranjeros en prisión; aspectos normativos y de intervención penitenciaria", en Derecho penitenciario.com http://www.derechopenitenciario.com/comun/fichero.asp?id=1333.

HERRERO HERRERO, C., Criminología: Parte General y Especial, Dykinson, Madrid, 2001.

LORENZO RUBIO, C., Cárceles en llamas, Virus, Barcelona, 2013.

MAPELLI CAFFARENA, B., Lecciones de Derecho Penitenciario, Ice, Madrid, 1983.

MUÑOZ CONDE, F., Derecho penal y control social, Fundación universitaria de Jerez, Jerez, 1985.

REDONDO ILLESCAS, S., "Psicología penitenciaria aplicada: los programas de rehabilitación en Europa”, Ponencia en las I Jornadas de Tratamiento Penitenciario, http://www.ub.edu/geav/contenidos/vinculos/publicaciones/public1_6/publicac_pdf/3_5 \%20Redondo\%20Illescas, \%20S\%20(2000).pdf, Peñíscola, 2000.

REDONDO ILLESCAS, S., SÁNCHEZ MECA, J., GARRIDO GENOVÉS, V., "Los programas sicológicos con delincuentes: la situación europea", en Psicothema Revista anual de Psicología, vol. 14, 2002.

RODRÍGUEZ NÚÑEZ, A., "Fórmulas para la resocialización del delincuente en la legislación y sistema penitenciario españoles", en http://www.uned.es/dpto-derechopolitico/arod.pdf

RODRÍGUEZ NÚÑEZ, A., "Prisión y derecho a la educación", en Anuario de la Escuela de Práctica Jurídica, núm. 1, 2006. 
VALDERRAMA BARES, P., "Los módulos de respeto en las cárceles, una revisión desde la educación social”, en Revista de Educación Social, núm. 22, enero 2016.

VALERO GARCÍA, V., "El tratamiento penitenciario: realidad y perspectivas", en El juez de vigilancia penitenciaria y el Tratamiento penitenciario, Estudios de Derecho Judicial, CGPJ, 2006.

VARELA, J., "La situación de las cárceles y la intervención en el contexto penitenciario", en ÁLVAREZ URÍA, F., (Ed.) Marginación e inserción, Endymion, Madrid, 1992.

YAGÜE OLMO, C., Madres en prisión. Historia de las Cárceles de Mujeres a través de su vertiente maternal, Comares, Granada, 2007. 